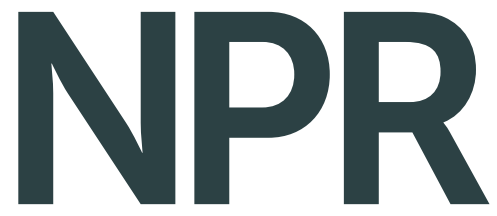

Natural Product Reports www.rsc.org/npr
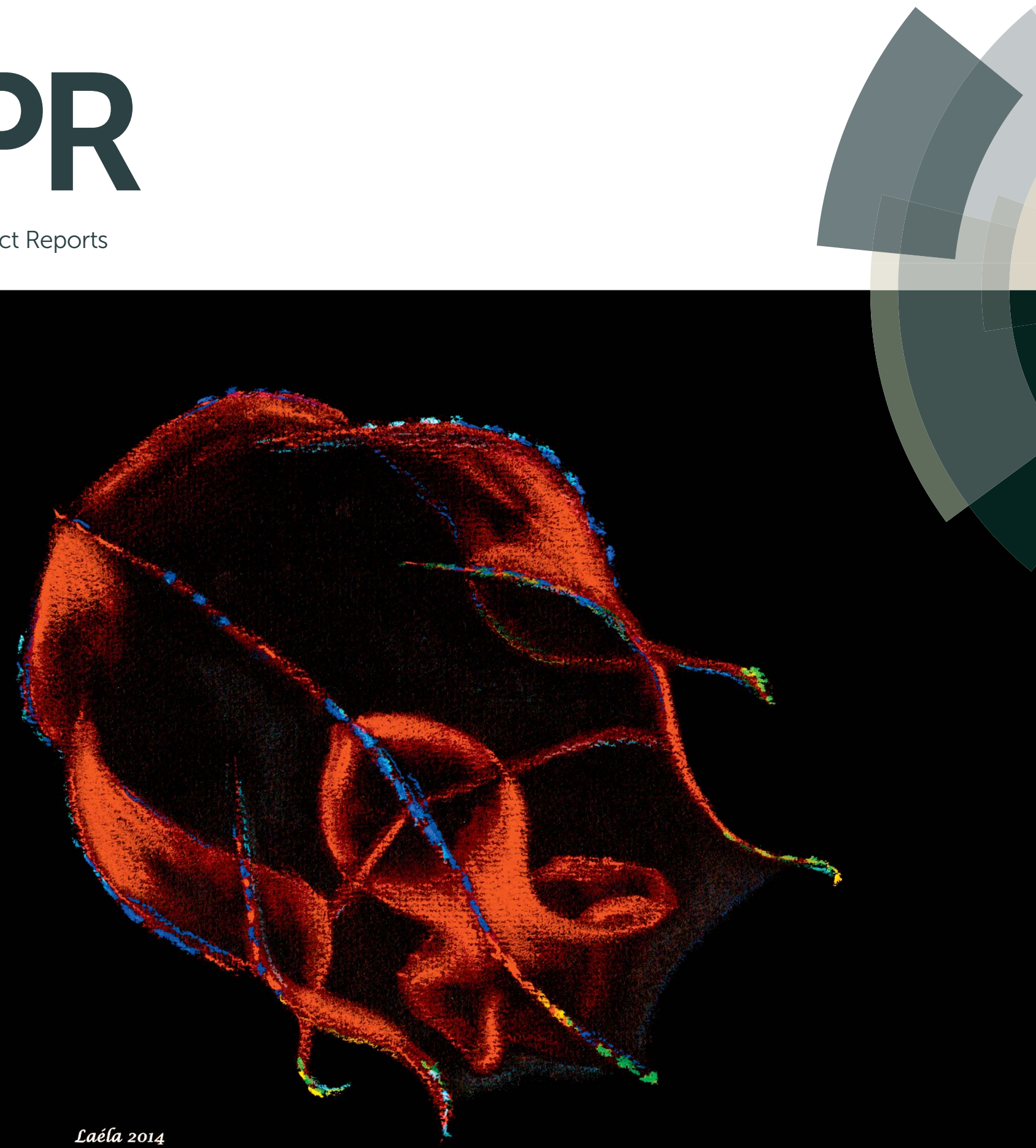

ISSN 0265-0568 
Cite this: Nat. Prod. Rep., 2014, 31, 612

\title{
Access to and use of marine genetic resources: understanding the legal framework $\dagger$
}

\author{
Laura E. Lallier, ${ }^{\star a}$ Oonagh McMeel, ${ }^{a}$ Thomas Greiber, $^{\mathrm{b}}$ Thomas Vanagt, $^{\text {a }}$ \\ Alan D. W. Dobson ${ }^{c}$ and Marcel Jaspars ${ }^{d}$
}

With the adoption of the Nagoya Protocol in 2010, an additional legal instrument under the Convention on Biological Diversity (1992), the legal landscape surrounding the access to and utilization of genetic resources will change. This is likely to impact working procedures for scientists, turning pre-existing

Received 18th November 2013 ethics into legal obligations. The aim of this article is to inform scientists on the global access and benefit-sharing framework which has been set by the Convention on Biological Diversity and its Nagoya Protocol, focusing specifically on their application to marine genetic resources for which the United Nations Convention on the Law of the Sea (1982) also has relevance.

www.rsc.org/npr

\section{Introduction}

Marine biodiscovery depends upon access to marine organisms, collectively termed marine genetic resources (MGR). Scientists, familiar with the potential challenges of collecting MGR samples in the marine environment, are often less aware of the legal and policy frameworks governing access to MGR. The Convention on Biological Diversity (CBD) ${ }^{1}$ and its Nagoya Protocol on Access to Genetic Resources and the Fair and Equitable Sharing of Benefits Arising from their Utilization (Nagoya Protocol), ${ }^{2}$ as well as the United Nations Convention on the Law of the Sea (UNCLOS) ${ }^{3}$ are of particular relevance in this regard.

This article will consider the CBD and its Nagoya Protocol, as well as the UNCLOS and examine how these legal frameworks impact marine scientific research, depending on the areas in which the MGR are collected and on the purpose of the research. Further it will provide a clear overview of the mechanisms in place and the steps which need to be taken in order to comply with these rules.

\subsection{The Convention on Biological Diversity and the Nagoya Protocol}

The CBD, which entered into force in 1993, addresses biodiversity irrespective of whether it is terrestrial or aquatic in

${ }^{a}$ eCOAST Marine Research, Esplanadestraat 1,8400 Ostend, Belgium. E-mail: info@ ecoast.be

${ }^{b} I U C N$ Environmental Law Centre, Godesberger Allee 108-112, D-53175 Bonn, Germany

${ }^{c}$ Environmental Research Institute, University College Cork, Cork, Ireland. E-mail: a. dobson@ucc.ie

${ }^{d}$ Marine Biodiscovery Centre, Dept. of Chemistry, University of Aberdeen, Old Aberdeen, AB24 3UE, UK

$\uparrow$ Electronic supplementary information (ESI) available: Authors' biographies. See DOI: $10.1039 / \mathrm{c} 3 \mathrm{np} 70123 \mathrm{a}$ origin. It has three main objectives: the conservation of biodiversity, the sustainable use of its components and, while declaring the sovereignty of states over their natural resources (article 3), it encourages the creation of access and benefitsharing (ABS) mechanisms when it comes to the exploitation or utilization of genetic resources (art. 1 \& 15). This last objective was devised to share the costs as well as the benefits of biodiversity conservation between developed and developing countries. Whilst ABS discussions are often limited to questions around the sharing of monetary benefits from research and development, it should be recognized that biodiscovery rarely results in lucrative patents and products. Thus, non-monetary benefits must also be considered. Furthermore, the objective of ABS is broader than promoting the sharing of the benefits gained from the use of genetic material. ABS is also about facilitating access to genetic resources (ref. 14 p. 28).

This is partly why the Conference of the Parties to the CBD adopted the Nagoya Protocol in 2010, which is an additional agreement to the Convention that is expected to enter into force in 2014. It further elaborates the CBD's ABS mechanism and promotes the development of worldwide ABS frameworks which will enable stakeholders to better understand and comply with national ABS procedures. In addition, the Protocol clarifies some aspects of the CBD, expressly including biochemical compounds within the scope of the framework and providing examples of both monetary and non-monetary benefits in its annex.

\subsection{The United Nations Convention on the Law of the Sea}

Because it has evolved through centuries of traditions and customary rules implicitly accepted and more or less effectively implemented by the various maritime actors, the law of the sea is a strongly rooted and particular field of law. The UNCLOS was adopted in 1982 (entered into force in 1994), and can be 
described as a codification of these customary rules, with some novel additions. In its simplest terms, the UNCLOS is a global and general framework setting the boundaries of states' jurisdiction and regulating the activities taking place there, including marine scientific research (MSR). Although it does not refer explicitly to genetic resources, it does address 'living', 'natural' or 'biological' resources in terms of conservation, exploitation and research (ref. 4 p. 150). Therefore a state that regulates MSR in its waters may impose certain access restrictions to the MGR within its jurisdiction.

It is important that scientists are aware of the distinct regimes governing access to MGR under both the CBD and its Nagoya Protocol on the one hand, and under the UNCLOS on the other hand. Compliance with the provisions a state may have in place under the UNCLOS does not ensure compliance with national ABS regime under the CBD and its Nagoya Protocol, and vice versa.

\section{Global common mechanism of ABS: a harmonized international framework}

As mentioned previously, when the Nagoya Protocol enters into force all state parties will be expected to have a national regime which meets global standards, thereby enabling users to know what to expect whenever they wish to access and utilize MGR. The Protocol's mechanism (Fig. 1) will impact bioprospecting activities independently of the way samples are initially acquired. When the genetic material is accessed from an 'ex situ' collection, i.e. a biorepository, then the access provisions of the CBD and the Nagoya Protocol apply. If, however, the genetic material is accessed 'in situ' via a sampling expedition then the UNCLOS provisions regarding MSR will also apply. Prior to considering the maritime specificities, it is first important to understand the ABS mechanism. As the Nagoya Protocol further elaborates the CBD's ABS provisions, the following explanations will mainly focus on the Protocol and not on the Convention.

\subsection{Prior informed consent and mutually agreed terms}

The ABS regime of the Nagoya Protocol is based on the negotiation of mutually agreed terms (MAT) in order to be granted access by the prior informed consent (PIC) of the providing state (art. 5 \& 6). Indeed, the applicant for PIC - the future user - must first comply with the domestic ABS requirements by negotiating MAT, which includes issues such as access conditions, material transfer rights and benefit-sharing agreements with the provider (Fig. 1). Often the first point of contact in a providing country is a partner institution to the user or to the research project. Both the CBD and the Protocol encourage the participation of nationals from the provider country on a foreign research project. The content of MAT has to be guided by domestic measures, which may require some specific aspects. The most probable and common requirements that can be expected are provided as examples by the Protocol (art. 6) and include: terms on benefit-sharing, terms on third party use, and terms on the change of intent.

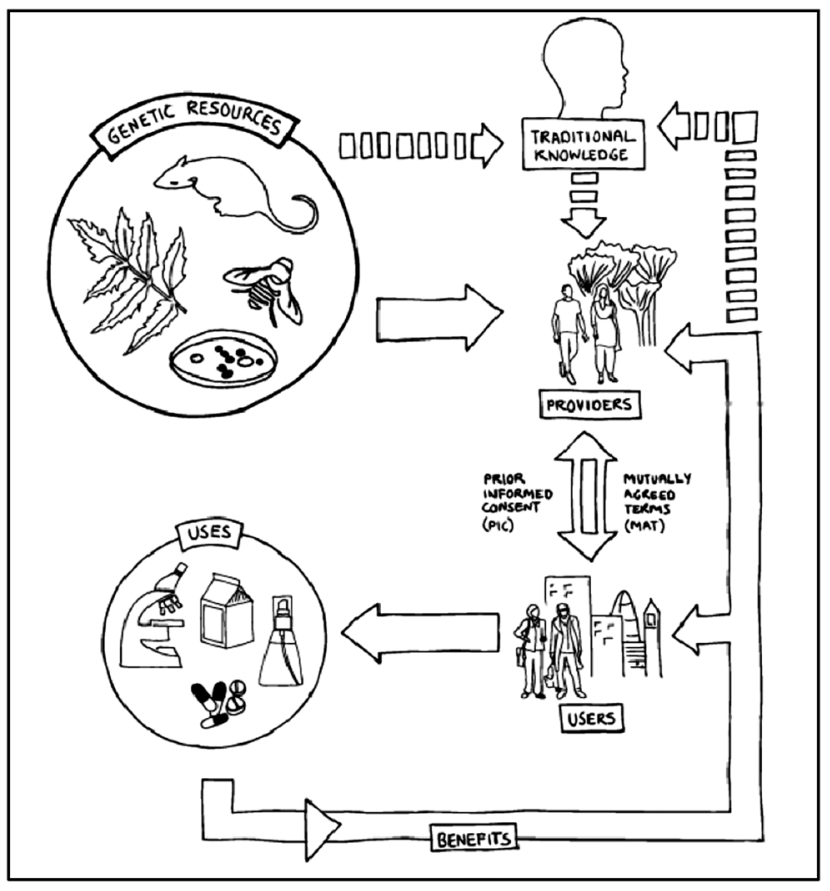

Fig. 1 ABS Framework in the Nagoya Protocol. Source: Factsheet on Access and Benefit-Sharing, Secretariat of the Convention on Biological Diversity, 2011. ${ }^{15}$

2.1.1 Subsequent third-party transfer. Subsequent thirdparty transfer is a key challenge of the negotiation process, that is the future transfer of the collected material and/or associated knowledge to a third party interested in the utilization of such material/knowledge, but not involved in the original negotiation of MAT. Given the nature of the biodiscovery pipeline, which may include multiple stakeholders, ${ }^{5}$ it is crucial to set clear terms on subsequent transfers from the onset. In this respect, the coastal state can either choose not to legislate, leaving the negotiations free, or it can regulate it, e.g. by imposing a comeback clause that would oblige the user to seek the consent of the source country authorities for each new transfer. Monitoring the utilization of the genetic resources is indeed important for ABS implementation.

2.1.2 Benefit-sharing. The benefit-sharing aspects of MAT are central to the negotiating process. As mentioned before, benefit-sharing does not only imply monetary benefits (such as payments of royalties), and indeed in most cases the main benefits will be non-monetary. Annex I of the Protocol provides examples of various types of benefits, and it is emphasized that benefits should as much as possible be directed towards the conservation and sustainable use of biodiversity (art. 9). The sharing of results, participation of nationals in product development, contributions to education and training in the providing country, technology and capacity transfer are some of the most common benefits currently found in MAT. Partnerships and contracts have long been customary practice in this respect, and can generally be considered as best practice for future benefit-sharing agreements. ${ }^{6,7}$ 
2.1.3 Change of intent. The biodiscovery process is a continuum which often begins with accessing MGR for basic research purposes but may evolve into a commercially driven process via an applied research phase. Delineating each of these phases can be difficult, however, identifying the change of intent is also an important aspect of MAT and must be considered. In this regard, a two phase approach may be recommended, as applicable: firstly negotiating MAT as a 'basic research agreement' with the possibility to secondly renegotiate a 'commercial development agreement' when there is a change of intent due to a new commercial interest arising from the research, and not only because a patent was obtained on a product. ${ }^{6}$ Indeed, because certain patents do not necessarily entail commercial consequences, the granting of such patents may not have any effect on the original bioprospecting permit if the original MAT were negotiated to provide for such a situation.

\subsection{Compliance requirements}

The negotiation of clear and legally certain MAT strongly influence the decisions of competent national authorities on whether to grant PIC to accessing MGR. The competent authority is the administration appointed by the state to officially approve the partnership's MAT. The PIC shall be granted in a written form that will eventually acquire the legal value of an internationally recognized permit (art. 17). This permit (or its equivalent) is the key document of the ABS mechanism, as it is meant to ensure legal certainty for both the user and the provider. It affords security to the provider, and enables the user to prove it has acquired the material legally and can thus progress safely and lawfully further along the biodiscovery pipeline.

This is of particular relevance for the user since the Nagoya Protocol requires that the parties provide for measures ensuring that genetic resources being utilized within their jurisdiction were acquired in compliance with the provider's ABS legislation (art. 15). Therefore benefit-sharing agreements are not simply an ethical practice, but are a legal obligation with all the relevant consequences in case of non-compliance. Potential consequences are: suspension or even cessation of the biodiscovery process, fines, inability to apply for a patent or to commercialize, etc. It is noteworthy that the European Union is currently elaborating a regulation to ensure that all users of genetic resources have complied with the domestic laws of providing countries, before conducting any research and development within the Union.

2.2.1 Competent national authorities (CNA). One of the consequences of the above described bilateral ABS approach is the involvement of state's competent authorities in the application process. The CNA might for instance be a department of the source country's Ministry of Environment that is responsible for granting PIC. This is in fact the case in Costa Rica, where the National Commission of Biodiversity Management grants the bioprospecting permits (www.conagebio.go.cr/). However, it might also be the case that multiple permits need to be obtained from different government institutions in order to get proper PIC, as is for example the case in Kenya. ${ }^{8}$ It all depends on the provider country's legal and institutional set-up. Considering MGR the situation with regard to the CNA may again differ. For example, in South Africa, the CNA for terrestrial bioprospecting is the Department of Environmental Affairs, but for MGR the Oceans and Coasts branch is competent, ${ }^{9}$ while in Norway it is the Ministry of Fisheries. ${ }^{10}$

Returning to the potential overlap between the UNCLOS and the CBD frameworks, where a state has implemented measures with respect to both, it is important to note that distinct national authorities might be competent for different aspects of the same activity. The onus is on the researchers to ensure that they have contacted all relevant authorities and established the procedures which they may be required to follow in order to access MGR.

\section{The UNCLOS and the Nagoya Protocol: overlapping frameworks for the collection of samples on site}

The provisions of the CBD and its Nagoya Protocol apply to biodiversity accessed within the national jurisdiction of coastal states. Since the UNCLOS grants jurisdiction to coastal states up to 350 nautical miles ( $\mathrm{nm}$ ) from the baselines, the Nagoya Protocol (which has to be implemented in respect of the UNCLOS according to art. 4) also applies in these maritime areas. And because both legal frameworks set their own rules to regulate either 'MSR' (UNCLOS part XIII) or 'Utilization of genetic resources' (NP art. 1), the situation is likely to result in the application of two distinct procedures for the same activity.

\subsection{Marine scientific research under the UNCLOS}

The UNCLOS grants various rights to the coastal states depending on the specific maritime areas (Fig. 2 for delimitations). The territorial sea can be compared to the prolongation of the state's territory: meaning the state has full sovereignty over these waters with all the discretion that it implies, including the regulation of MSR (art. 2). But the jurisdiction of coastal states over their natural resources extends far beyond the $12 \mathrm{~nm}$ of the territorial sea. Indeed, within the $200 \mathrm{~nm}$ of the exclusive economic zone (EEZ) as well as on the

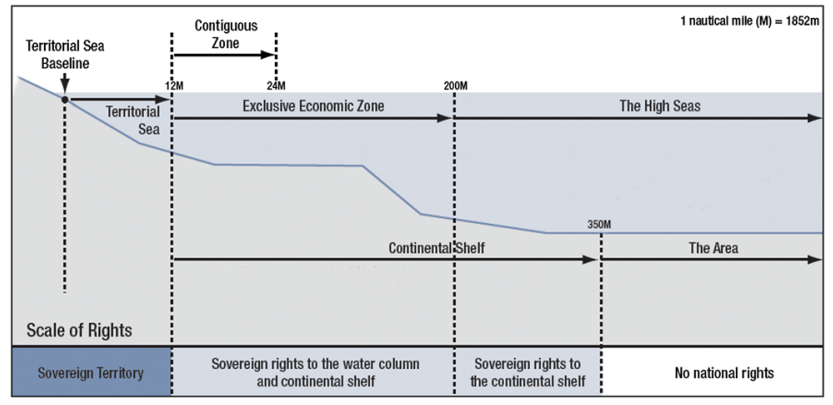

Fig. 2 Maritime Boundaries in the UNCLOS. Source: Arctic Council, Arctic Marine Shipping Assessment 2009 Report (Tromsø, Norway: 2009), p. 52, available at: www.pame.is/images/stories/PDF_Files/ AMSA_2009_Report_2nd_print.pdf. 
continental shelf (CS) which can be up to $350 \mathrm{~nm}$, the coastal state is granted exclusive rights, which must be differentiated from sovereignty in the sense that such rights only apply to specific activities (i.e. protection of the environment, or the exploration and exploitation of natural resources).

One of the rights granted to the coastal state relates directly to MSR. Indeed, the coastal state has to be notified six months in advance of any MSR project requiring access to its EEZ or CS. It also has the right to require the participation of national observers in the project (art. 248). Because this procedure is more related to the supervision of the traffic and ongoing activities within national jurisdiction than to the regulation of access to resources for any applied purpose and exploitation, the competent authority responsible for granting the authorization is often the navy. For instance, in Chile the Office of the Commander-in-Chief of the Navy grants the authorization following consultation with the Navy Hydrographic and Oceanographic Service. ${ }^{11}$ Consent from the coastal state is easily acquired since one of the UNCLOS objectives is to promote MSR, and the state's consent should always be granted 'under normal circumstances' (art. 246). ${ }^{4}$ Even though it is beyond the scope of this article to discuss what can be considered as abnormal circumstances, it is noteworthy that the discretionary power of the coastal state to refuse the access of a cruise campaign to its waters in cases where there might be a 'significant effect' on the exploitation of natural resources (art. 246).

\subsection{In situ marine genetic resources under the Nagoya Protocol}

Since states have sovereignty over the natural resources found within their jurisdiction under the $\mathrm{CBD}$, it is very important to refer to the Convention and its Nagoya Protocol together with the UNCLOS to understand where this jurisdiction extends. Within the $200 \mathrm{~nm}$ limits of the EEZ and CS it is clearly stated that the coastal state has jurisdiction over all 'natural resources' (art. $56 \& 77$ ). However it is worth mentioning that the jurisdiction of states can sometimes extend up to $350 \mathrm{~nm}$ (art. 77), after the extension of the CS was submitted to the Commission on the Limits of the CS (Annex II). At present, only 18 states have acquired such extended rights (www.un.org/ depts/los/clcs_new/clcs_home.htm). These rights grant states jurisdiction over the 'sedentary species' (benthos) of the seabed therein. However, for the water column above the extended CS the freedom of the High Seas applies. Therefore, if benthic organisms are sampled from the seabed within such extended jurisdiction, the appropriate consent of the coastal state must be sought.

Consequently, what should be borne in mind is that PIC and MAT are required for any activity related to MGR up to $200 \mathrm{~nm}$ (water column) or $350 \mathrm{~nm}$ (extended CS), and that the sole authorization of conducting research will not be sufficient. Two permits, probably granted by different authorities, may therefore be required: an authorization to conduct marine research within the coastal state's jurisdiction and a permit to access and utilize MGR. However, it is not clear when MSR becomes bioprospecting, and when or, to what extent, the commercial intent

becomes decisive for the definition of the activity. To further complicate matters national legislations implementing the Protocol could well provide different answers to this question from one country to another, as several 'definitions' of bioprospecting exist globally. It is thus probably safest to systematically enter into a relationship with a partner from the source country and include a change of intent clause, i.e. to foresee any subsequent and unplanned future commercial exploitation.

\section{Concluding remarks}

Although the Nagoya Protocol is a new legally binding instrument which will certainly add administrative layers to the conduct of MSR and related bioprospecting activities, it will also bring more legal certainty to the biodiscovery pipeline and, through the negotiation of agreements, avoid the misappropriation and misuse of genetic resources. ${ }^{12}$ In this regard, all parties involved in the value chain of the utilization of legally acquired genetic resources should benefit from the security thus provided and pursue their work safely. To further encourage good practice, we would recommend that relevant scientific journals may wish to adopt a policy whereby acceptance of a research paper which relates to the access or utilization of a genetic resource would be contingent on a statement ensuring compliance with existing regulations.

It is worth mentioning that, while waiting for the entry into force of the Protocol and the ratification of the parties, some uncertainties remain. These are, amongst others, the repartition of MGR in areas involving several providing states or in situations where the same MGR can be found within and beyond national jurisdictions. It is also noteworthy to emphasize the regime of the international high seas and deep seabed areas. Although states are obliged to disseminate information and knowledge from MSR in these areas - which could be compared to a form of non-monetary benefits similar to those under the CBD and its Nagoya Protocol - the access to genetic resources beyond national jurisdiction remains free at the moment. This is likely to change in the next decade as current discussions within the United Nations General Assembly appear to be heading towards the possible elaboration of an additional agreement to the UNCLOS with respect to ABS of MGR in international waters. ${ }^{\mathbf{4}, 13}$

\section{Abbreviations}

ABS

Art.

CBD

CNA

CS

EEZ

MAT

MGR

MSR

PIC

UNCLOS
Access and Benefit-Sharing

Article (of a Convention)

Convention on Biological Diversity

Competent National Authority

Continental Shelf

Exclusive Economic Zone

Mutually Agreed Terms

Marine Genetic Resources

Marine Scientific Research

Prior Informed Consent

United Convention on the Law of the Sea 


\section{Acknowledgements}

This work was supported by the PharmaSea project funded by the EU Seventh Framework Programme, and reflects only the authors' views. Contract number 312184. www.pharma-sea.eu.

\section{Notes and References}

1 Convention on Biological Diversity, Rio de Janeiro, 22nd may 1992. Entered into force 29th Dec. 1993, 193 parties on 3.10.13. www.cbd.int/convention/text/.

2 Nagoya Protocol on Access to Genetic Resources and the Fair and Equitable Sharing of Benefits Arising of their Utilization, Nagoya, 29th Oct. 2010. Yet to enter into force, expected 2014: www.cbd.int/abs/text/.

3 United Nations Convention on the Law of the Sea, Montego Bay, 10th Dec. 1982. Into force 16th Nov. 1994, 166 parties on 20.09.13. www.un.org/Depts/los/index.htm.

4 C. Salpin, The Law of the Sea: A before and an after Nagoya?. In The 2010 Nagoya Protocol on Access and Benefit-sharing in Perspective, Implications for International Law and Implementation Challenges, by E. Morgera, M. Buck and E. Tsioumami, Martinus Nijhoff Publishers 2013, p. 149-183.

5 S. Laird and R. Wynberg, Biosciences at a Crossroads: Implementing the Nagoya Protocol on Access and BenefitSharing in a Time of Scientific, Technological and Industrial Change, Secretariat of the CBD Policy Brief, 2012.

6 G. M. Cragg, F. Katz, D. J. Newman and J. Rosenthal, The impact of the United Nations Convention on Biological Diversity on natural products research, Nat. Prod. Rep., 2012, 29, 1407-1423.
7 G. M. Cragg, F. Katz, D. J. Newman and J. Rosenthal, Legal and Ethical Issues Involving Marine Biodiscovery and Development, in Handbook of Marine Natural Products by E. Fattorusso, W.H. Gerwick and O. Taglialatela-Scafati, Springer Netherlands Pub., 2012, 1314-1342.

8 E. C. Kamau and G. Winter, Streamlining Access Procedures and Standards. In Genetic resources, traditional knowledge, and the law: solutions for access and benefit sharing, by E.C. Kamau and G. Winter. Earthscan 2009, p. 365-379.

9 Bioprospecting Guidelines, South Africa: www.cbd.int/abs/ measures/group $/$ ? code $=$ za.

10 Marine Resources Act no 37, 2009, Norway: www.cbd.int/abs/ measures/group/?code $=$ no.

11 Supreme Decree no 711, August 22nd 1975, Chile: http:// www.shoa.cl/tramites/decreto711_ing.pdf.

12 C. Chiarolla, Biopiracy and the Role of Private International Law Under the Nagoya Protocol 2012, Working Paper no. 02/ 12, IDDRI, Paris, France, 20p.

13 D. Leary, Moving the Marine Genetic Resources Debate Forward: Some Reflections, The International Journal of Marine and Coastal Law, 2012, 27(2), 435-448.

14 T. Greiber, S. P. Moreno, M. Åhrén, J. N. Carrasco, E. C. Kamau, J. C. Medaglia, M. J. Oliva, F. Perron-Welch in cooperation with N. Ali and C. Williams, 2012. An Explanatory Guide to the Nagoya Protocol on Access and Benefit-Sharing. IUCN, Gland, Switzerland. xviii +372 pp. Available at: http://data.iucn.org/dbtw-wpd/edocs/EPLP083.pdf.

15 ABS Information Kit produced and published by the CBD secretariat (2011). Available at: www.cbd.int/abs/awarenessraising/. 